\title{
Knowledge of Breast Cancer and Screening Methods among Rural Women in Southwest Nigeria: A Mixed Method Analysis
}

\author{
Rowland Edet $^{1 *}$, Oluwayimika Ekundina ${ }^{1}$, Obasanjo Afolabi Bolarinwa ${ }^{2}$, \\ Julianah Babajide ${ }^{1}$, Juliet Amarachukwu Nwafor ${ }^{3}$ \\ ${ }^{1}$ Department of Sociology, University of Ibadan, Ibadan, Oyo State, Nigeria \\ ${ }^{2}$ Department of Public Health Medicine, University of KwaZulu-Natal, South Africa. \\ ${ }^{3}$ Lagos Business School, Pan-Atlantic University, Lagos, Nigeria \\ *Corresponding author email: edetr24@gmail.com
}

Received: 23 May 2020 / Accepted: 04 August 2020 / Published: 14 August 2020

\begin{abstract}
The objective of this study was to assess the awareness of rural women on breast cancer and its screening methods in Southwest Nigeria. Descriptive cross-sectional survey design with the aid of a semi-structured questionnaire was used to generate data among 422 rural women in selected communities in Egbeda local government area of Ibadan. The qualitative data was generated through in-depth interviews among rural women and key informant interviews among health workers in the communities. The study revealed that only $63.7 \%$ were aware of breast cancer screening methods compared to $31.6 \%$ who were not aware of it. The commonly known screening method among women in the study was breast self-examination $(66.7 \%)$. Some believed that breast cancer is used as a form of spiritual attack to punish women. Knowledge of breast cancer etiology was also low. The major source of information on breast cancer was radio. The study concluded that health education and programs targeting rural women should be adopted to increase their awareness of breast cancer.
\end{abstract}

Keywords: Breast cancer, breast cancer screening, Rural, Women, Nigeria

\section{Introduction}

Breast cancer is responsible for the high mortality of women in Nigeria (Tobin and Okeowo, 2014; Oche et al., 2012). Poor knowledge of breast cancer screening influences the high mortality rate among women (Onwere et al., 2009). As studies have revealed, poor health behaviour on breast cancer detection accounts for high deaths of women (Ajayi et al., 2013). A study in a rural community in Nigeria reported that $21.4 \%$ of the women knew about the symptoms presented by breast cancer. Also, about $40 \%$ ascribed breast cancer to spiritual causation, while $25.9 \%$ were of the view that breast cancer is infectious. It was worrisome to note that only $9.1 \%$ attended a breast examination at a hospital or clinic with none having no history of mammography examination (Okobia et al., 2006). This shows that many women in Nigeria see no need for any clinical breast cancer examination as long as they have no breast problem.

In another study conducted among women in Benin, Nigeria, the majority (92.6\%) were ignorant of breast cancer screening methods (Ifeanyichukwu, 2015). Similarly, one study reported that $25 \%$ of the nurses in his study were not exposed to the risk factors that occur due to breast cancer. However, breast cancer was identified as a disease that cannot be transmitted from one person to the other, and that it had nothing to do with spiritual causation (Salaudeen $e$ t al., 2009). In another study with health workers, the majority $(72 \%)$ viewed screening methods as time-consuming, and few (6\%) practiced it (Haji-Mahmoodi et al., 2008). According to a study among rural women in Southwest Nigeria, majority $(73.7 \%)$ had no knowledge of breast cancer early signs, $90.7 \%$ did not know that breast cancer can be treated if detected early, only $6.4 \%$ identified breast self-examination and clinical breast examination, and no one could identify mammography (Oluwatosin and Oladepo, 2006). 
Knowledge of Breast Cancer and Screening Methods among Rural Women in Southwest Nigeria: A Mixed Method Analysis

Also, a study in Canada revealed that $12 \%$ and $49 \%$ of the South Asian women had carried out breast selfexamination and clinical breast examination respectively in the last six months, while $47 \%$ never had mammography screening (Donelly et al., 2013). This shows that while more women practice breast cancer examination, the reverse is the case in less developed countries like Nigeria. Therefore, the main objective of this article is to examine the extent to which rural women in Ibadan Southwest Nigeria are aware of breast cancer and its screening techniques.

\section{Research Methodology}

The study was carried out in Ibadan Southwest Nigeria using a descriptive design. The choice of Ibadan for the study is due to the presence of both traditional and orthodox pathways of healthcare, which women often utilize for their health needs. Using the Cochran sample size formula for an unknown population, 422 women aged 16-65 were selected for the study. The selection of respondents for the study was done using multi-stage sampling. First, Egbeda local government was purposively selected. Second, three wards, namely Awaaye, Owo Baale, and Egbeda Central, were randomly selected from the local government. The final stage was a systematic random selection of households. Data was collected for this study using both quantitative and qualitative methods. The quantitative data adopted a semi-structured questionnaire, while in-depth interviews and key informant interviews (among health workers) were used to generate the qualitative data. The quantitative data were presented in frequencies and percentages, while the in-depth and key informant interviews were content analysed.

\section{Data and Results}

This section presents the descriptive statistics of the demographic characteristics of the respondents. Discussions that are in accordance with the study objective were also presented.

\subsection{Socio-demographic Data}

Table 1 reveals that more than half $(51.9 \%)$ of the respondents were between the ages of 16 and $30,28.4 \%$ were between the ages of 31 and 40, while $8.5 \%$ were 51 years and above.

Table 1: Socio-demographic Characteristics of Respondents $(N=422)$

\begin{tabular}{|c|c|c|c|}
\hline \multicolumn{2}{|c|}{ Variable } & Frequency & Percentage \\
\hline \multirow[t]{4}{*}{ Age } & $16-30$ & 219 & 51.9 \\
\hline & $31-40$ & 120 & 28.4 \\
\hline & $41-50$ & 47 & 11.1 \\
\hline & 51 years and above & 36 & 8.5 \\
\hline \multirow[t]{3}{*}{ Marital status } & Single & 143 & 33.9 \\
\hline & Married & 214 & 50.7 \\
\hline & Separated/Widowed/Divorced & 57 & 13.5 \\
\hline \multirow[t]{3}{*}{ Religion } & Christianity & 251 & 59.5 \\
\hline & Islam & 129 & 30.6 \\
\hline & Traditional & 42 & 10.0 \\
\hline \multirow[t]{4}{*}{ Educational status } & Non-formal & 141 & 33.4 \\
\hline & Primary & 82 & 19.4 \\
\hline & Secondary & 170 & 40.2 \\
\hline & Tertiary & 29 & 6.9 \\
\hline \multirow[t]{8}{*}{ Occupation } & Self-employed & 169 & 40.0 \\
\hline & Full-time housewife & 39 & 9.2 \\
\hline & Civil servant & 40 & 9.5 \\
\hline & Public servant & 17 & 4.0 \\
\hline & Unemployed & 28 & 6.6 \\
\hline & Artisan & 53 & 12.6 \\
\hline & Farmer & 38 & 9.0 \\
\hline & Student & 38 & 9.0 \\
\hline \multirow[t]{4}{*}{ Income per month } & $\mathrm{N} 18,000$ and below & 222 & 52.6 \\
\hline & $\mathrm{N} 18,001$ to $\mathrm{N} 29,000$ & 134 & 31.6 \\
\hline & $\mathrm{N} 29,001$ to $\mathrm{N} 49,000$ & 45 & 10.7 \\
\hline & $\mathrm{N} 50,000$ and above & 21 & 5.0 \\
\hline
\end{tabular}


Rowland Edet et al., Adv. J Social Sci.; Vol. 7, Issue 1, pp: 81-91, 2020

This finding implies that most participants in this study were young. When respondents were asked to indicate their marital status, $50.7 \%$ were married, $33.9 \%$ were single, while $13.5 \%$ were either separated, widowed, or divorced. Respondents were asked to indicate their religious beliefs in the study location. Findings showed that more than half $(59.5 \%$ ) practiced Christianity, $30.6 \%$ practiced Islam, while $10 \%$ were traditional worshippers.

The educational attainment of respondents in the study area showed that $33.4 \%$ possessed non-formal education, $40.2 \%$ had completed secondary school, while $19.4 \%$ had primary education. The implication of this is that there was a low level of education in the study area, and this could have an impact on breast cancer awareness in the study area. Furthermore, $40 \%$ of the respondents were self-employed, $12.5 \%$ were artisans, civil servants accounted for $9.5 \%$, while $6.6 \%$ of the respondents were unemployed without any source of income. It can be established that most respondents were economically active and could provide for their daily needs for survival. The income distribution of respondents showed that $52.6 \%$ earned less than $\$ 18,000$ month, $31.6 \%$ earned $\$ 18,001$ to $\$ 29,000$, while $10.7 \%$ earned $\$ 29,001$ to $\$ 49,000$.

\subsection{Breast Cancer Awareness}

Table 2 reveals that the majority (81\%) had knowledge of what breast cancer is about, while the opposite was the case for $15.4 \%$ of the respondents. It was also revealed that $69.4 \%$ saw breast cancer as a deadly disease, $22.5 \%$ believed that breast cancer is caused by poor hygiene, $21 \%$ indicated that it could be cured if detected early, while $7.3 \%$ attributed breast cancer to a form of spiritual attack. Furthermore, it was reported that $54 \%$ stated that breast cancer could be detected early, while $25.6 \%$ reported otherwise. It was also revealed that $25.3 \%$ of the respondents opined that it is good to do breast cancer screening, $11.8 \%$ expressed that they were scared to perform breast cancer screening, 13\% revealed that they did not have the financial capacity to go for a breast cancer screening exercise, while $20.1 \%$ reported that they could not go for breast cancer screening.

Table 2: Knowledge of Breast Cancer $(N=422)$

\begin{tabular}{|l|l|l|}
\hline Awareness of breast cancer & Frequency & Percentage \\
\hline Those that are aware of breast cancer & 342 & 81.0 \\
\hline Those that are not aware of breast cancer & 65 & 15.4 \\
\hline Those that are partially aware of breast cancer & 15 & 3.6 \\
\hline Perception on breast cancer & Frequency & Percentage \\
\hline It is a disease that is caused by poor hygiene & 95 & 22.5 \\
\hline It is a deadly disease & 293 & 69.4 \\
\hline Early detection can be cured & 89 & 21.0 \\
\hline It is an inherited disease & 24 & 5.7 \\
\hline It is a disease that is common among women. & 24 & 5.7 \\
\hline It is a disease caused by spiritual attack & 31 & 7.3 \\
\hline Possible Early Breast Cancer Detection & Frequency & Percentage \\
\hline It is possible & 228 & 54.0 \\
\hline It is not possible & 108 & 25.6 \\
\hline I do not know & 50 & 11.8 \\
\hline Attitude toward breast cancer screening & Frequency & Percentage \\
\hline I am too old for breast cancer screening & 24 & 5.7 \\
\hline Fear & 70 & 11.8 \\
\hline Breast cancer screening is good & 107 & 25.3 \\
\hline No money & 75 & 13.0 \\
\hline I cannot go for breast cancer screening & 85 & 20.1 \\
\hline I have not heard of any screening method & 21 & 5.0 \\
\hline
\end{tabular}


Results from the qualitative data revealed that breast cancer is caused by putting money inside the brassiere as well as a spiritual attack. This was captured by one of the respondents below:

I have heard of breast cancer before. It is caused by putting money in the bra, putting on a tight bra, and sleeping with the bra. It can be used spiritually to punish others; you would even know that it is spiritual from its look. It can be treated if one gets to know before spreading to the other breast, the person can go to the hospital, and they can remove it. It can also be inherited.

(Female/44 years/Awaye/IDI).

Another respondent stated thus:

I heard of breast cancer from the radio. On the causes, it could be a result of a spiritual attack. And it is untreatable because those that I have seen that had the diseases in this community died no matter what. The only knowledge I have is that if there is any infection, the person should take care of it early.

(Female/ 52 years/Owo Baale/IDI).

Others believed breast cancer was not caused by the spiritual attack but by bacteria infection and can be treated if detected early. A respondent had this to say:

I have heard of breast cancer before. Breast cancer is treatable if it is detected early, and the necessary actions are taken. Breast cancer can be caused by a worm or bacterial infection, which, if not well taken care of, can lead to breast cancer. It can't be inherited.

(Female/ 65 years /Owo Baale)

One of the interviewees who once had breast cancer attributed it to poor hygiene and putting money in the bra and even putting mobile phones in the breast, as is the practice among older women in the rural area. But they, however, noted that breast cancer could be treated if noticed early. She narrated her experience thus:

I have heard of breast cancer before. Poor hygiene and putting money in the bra could cause it. I once had breast pains after breastfeeding my baby. I noticed I was having pains in my breast, and it looked like milk was still stored there. I told my elder sister, and she took me to a hospital where I was given drugs. The drugs were quite expensive, but it worked as that was the last I heard of it. Women should not put mobile phones in their brassiere. It is not a spiritual disease; it can only be caused by the person herself.

(Female/30 years/Awaye/IDI)

From the finding above, breast cancer can be treated if noticed early enough. Other studies have discovered that evil spirits had nothing to do with breast cancer, and it is not a big problem if there are excellent treatment facilities at the earlier stage of its presentation (Azage et al., 2013; Parvani, 2011).

Figure 1 reveals that $61.9 \%$ reported that they learned about breast cancer through radio, $8.9 \%$ said that they knew about it through the hospital, 5.9\% stated that it was through television, 5.2\% indicated that it was through church while $4.8 \%$ reported other sources like personal experience, face to face discussions, friends, school, seminars, word of mouth and workplace. 
Rowland Edet et al., Adv. J Social Sci.; Vol. 7, Issue 1, pp: 81-91, 2020

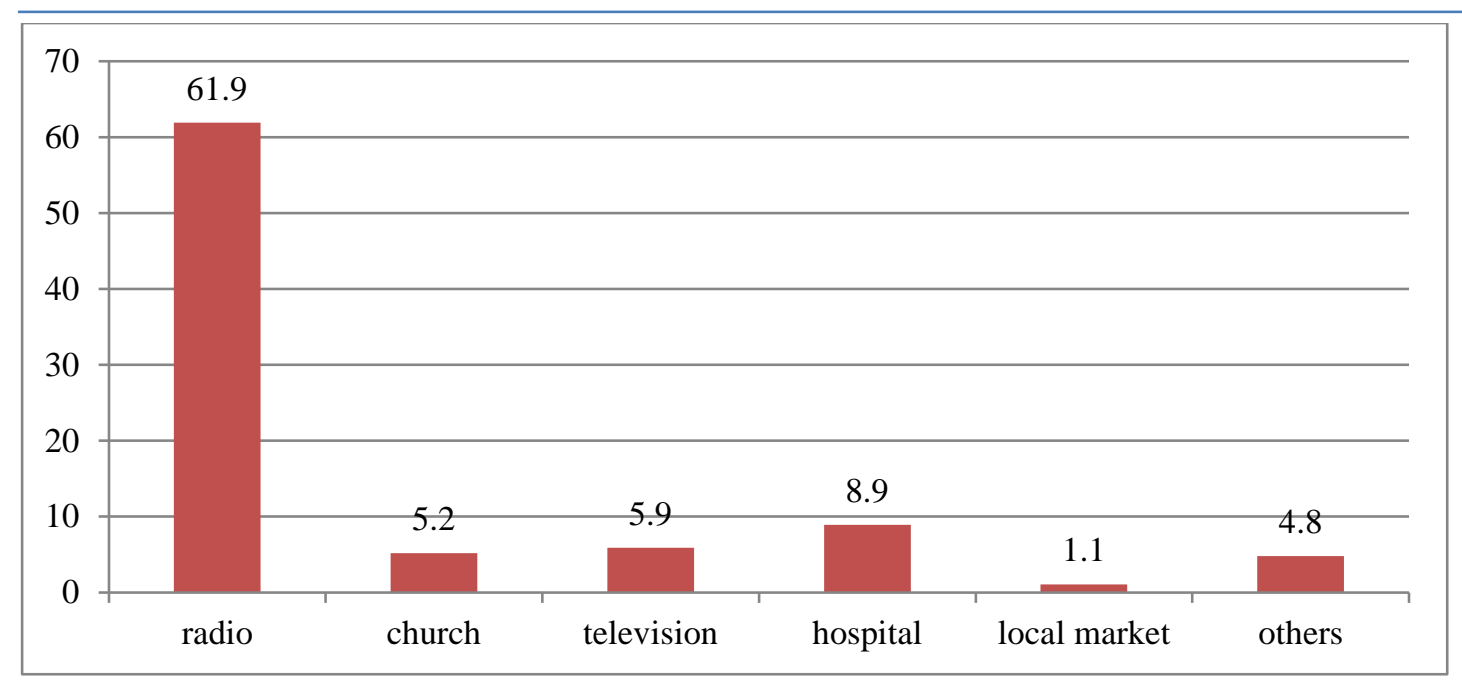

Figure 1: Source of Knowledge of Breast Cancer

It was discovered that there were differing opinions on breast cancer; hence, awareness about breast cancer was not at the same rate as others, as some might have had the experience or attended an awareness program before. For instance, an interviewee during an in-depth interviewee session noted:

I have heard about breast cancer on TV. I also heard that it is usually expensive to treat. Bacteria or worms cause it. It is not spiritual, but as a result of most foods, we eat. Early detection is treatable. It is not inherited. For the first child, a woman can have a swollen breast because women have different bacteria/worms in their breasts and if they use hot water, it will go down.

(Female/ 40 years/Awaye/IDI)

The above statement shows that the significant sources of information on breast cancer were through radio and television. Elsewhere, studies had identified television and radio as the dominant medium through people derived information on breast cancer (Bell et al., 2011)

An interview with a community worker revealed that some of the community members had low knowledge of breast cancer and how deadly it is. However, the knowledge gap is bridged through health education by community health workers. This problem could be attributed to the low literacy level of women living in rural areas as well as low health education among rural women. Against this background, the interviewee opined:

Some of them are aware, while some are ignorant basically because they are illiterate. They do not know the causes of breast cancer and the threat it poses. They are not fully aware of the perceived threat, even though they commonly believe that it is a deadly disease. I cannot fully say that they have sufficient knowledge like my colleague has said their knowledge about breast cancer is quite low. They know that it can lead to death, but they do not know the causes. We are the ones that tell them the causes that when they come to the clinic for injection/vaccination for their children. Also, when they come for antenatal care, we give them health talks.

(Male/37 years/Owo Baale/Community health worker/KII)

Another health worker maintained that despite the breast cancer awareness program by the government, many women in the community were not very knowledgeable about what causes breast cancer, but only perceived it to be deadly. She explained: 
Not all women are aware of the health issues breast cancer poses. The majority of them are not that even aware. Even though Patience Jonathan (former Nigerian First Lady) organized an awareness program and also gave them some cream/equipment to use to check their breast, hardly have I seen anyone that used it here. They just drop it somewhere. They do not know the causes of breast cancer but only know that it is deadly and dangerous. I do not think that they are aware of the perceived threat. They have no sufficient knowledge about the disease because they do not have a full understanding of the cause.

(Female/44 years/Awaye/Community health worker/KII)

Indeed, breast cancer awareness determines exposure to breast cancer examination among rural women. Studies on gender and breast cancer have shown that African women do not have in-depth knowledge of the inherent dangers or consequences associated with breast cancer (Taha et al., 2014). This low knowledge, as other studies have reported, accounts for the high death rates of women who suffer from breast cancer (Yakubu et al., 2014). Therefore, there is a need for breast cancer awareness programs targeting women, especially in rural areas. With the intervention of the government and non-governmental agencies, such programs would be essential to educate women on the strategies that can be adopted to prevent breast cancer.

\subsection{Breast Cancer Screening Awareness}

Figure 2 shows that $63.7 \%$ had heard of breast cancer screening, while $31.6 \%$ were not aware. This is worrisome because, for close to average, to be unaware of methods of breast cancer examination was indeed a problem.

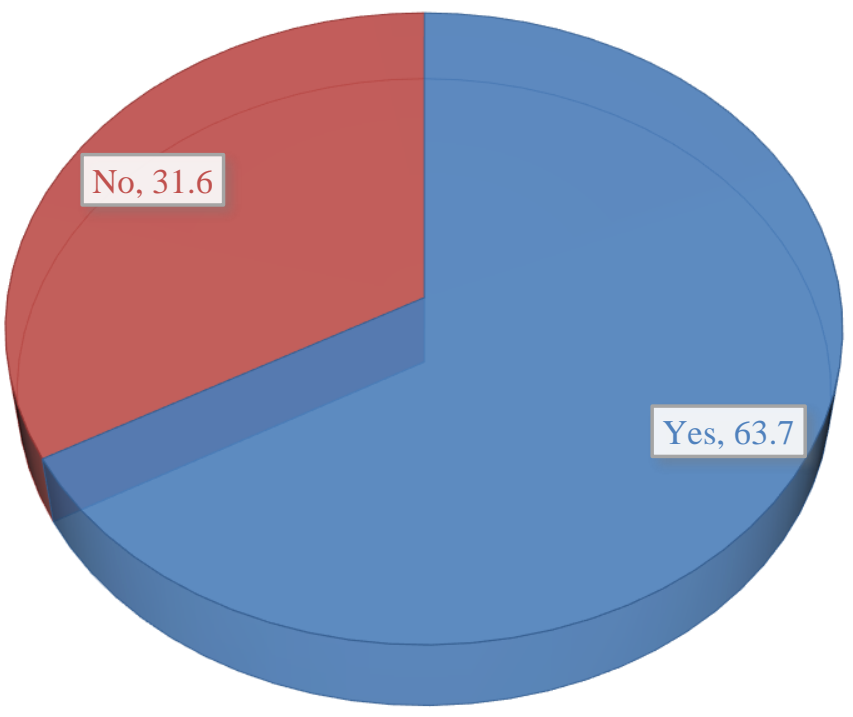

Figure 2: Knowledge of Breast Cancer Screening

Figure 3 reveals that more $(66.7 \%)$ of the women reported having heard of breast self-examination, 15.1\% reported ultrasound, while $14.5 \%$ identified mammography. The implication of this finding shows that because of the low level of literacy, respondents were not exposed to other methods of breast cancer screening. 
Rowland Edet et al., Adv. J Social Sci.; Vol. 7, Issue 1, pp: 81-91, 2020

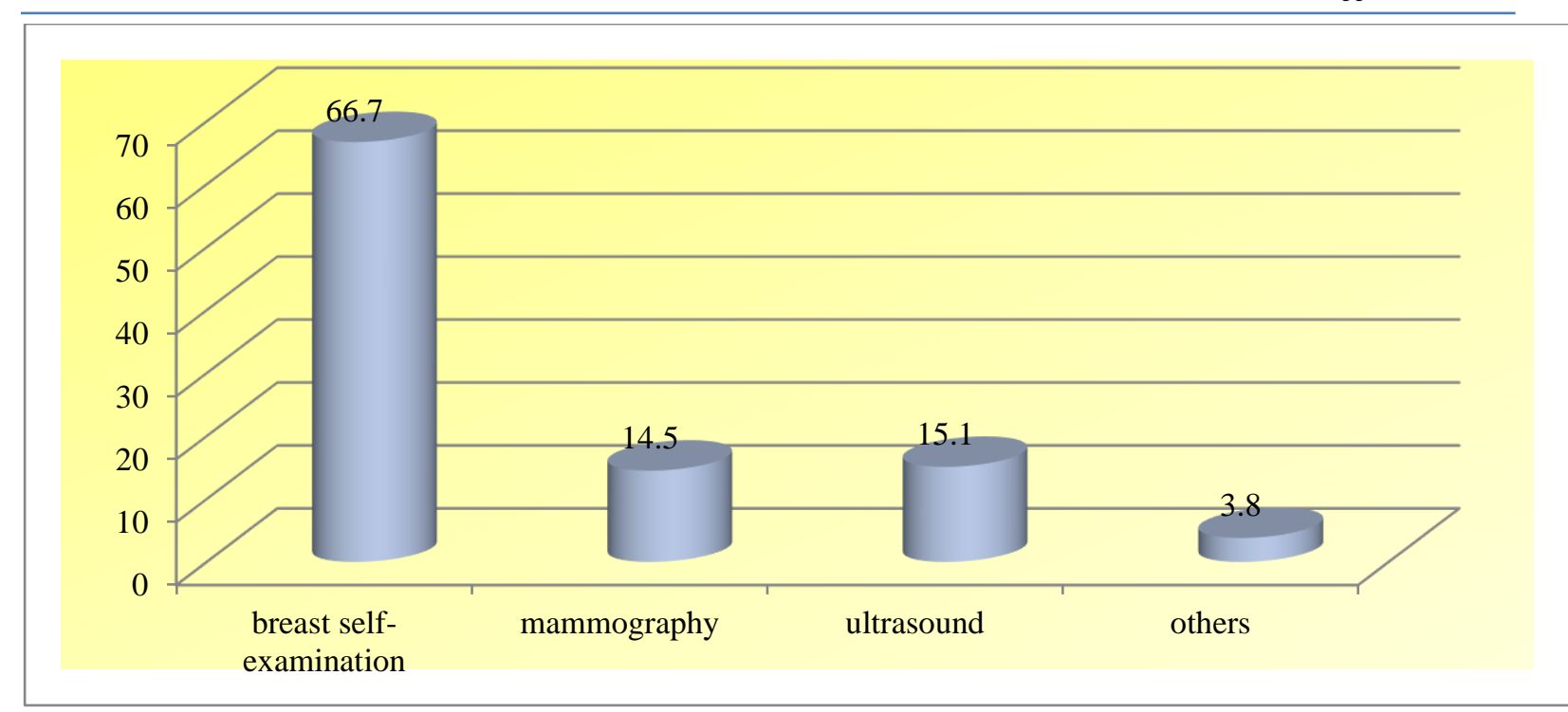

Figure 3: Commonly Known Breast Cancer Screening Methods

The interview sessions with the respondents showed that some of them were aware of breast cancer screening. Sources of information on breast cancer screening were derived from health awareness programs that educated the women breast cancer screening. This was expressed thus:

I have heard of breast cancer screening. I went for a seminar/awareness program on breast cancer two years ago, and we were taught different ways. We were given kits that they said that we should be using it on our breast even though I cannot remember, but they mentioned the use of one's hands to check the breast (she demonstrated breast self-examination), then the one of taking pictures on the breast (breast ultrasound) and the use of the machine (mammography).

(Female/39 years/Egbeda/IDI)

However, some of the respondents had low knowledge of breast cancer screening. This was evidenced in the findings as revealed by a respondent who narrated that the doctor who examined and treated the lump in her breast did not explain to her about any breast cancer screening. She stated thus:

I do not know about any breast cancer screening. When I had a lump in my breast, the doctor just checked my breast and said that I had breast cancer. He did not do any scan or test for me. He just treated me. Because my breast was swollen, so he just checked. No operation or anything. The doctor did not even explain anything to me on breast cancer screening. I did not go to the hospital immediately when I noticed the swelling because I thought it caused by breastfeeding. It was when it became unbearable that I went to the hospital. I was just given a drip and injection. But when the treatment was insufficient, I came to the village, and the traditional doctor gave me an herbal mixture to use.

(Female/29 years/Owo Baale/IDI)

From the above, we found that rural women were ignorant of the techniques used in breast cancer detection. This is quite disheartening as the health officials that are supposed to give adequate information on breast cancer did see it as part of their job. This can go a long way to reduce the trust and belief in medical practitioners and hence, make people result in other means due to availability and accessibility. In line with this finding, research has shown that women in rural areas do not receive adequate health education from health workers, explaining their poor knowledge of breast cancer screening methods (Obaji et al., 2013; Akhigbe and Omuemu, 2009) 
The interview with the community health workers revealed that even though there were no breast cancer screenings in the health centers, members of the community rarely visited the health center for scans or tests on any medical condition. A health worker corroborated the finding this way:

Since I have been here, only one or two persons have visited this place. One of them came with a scan, and I referred her to a State hospital. The other person came, but we could not follow up on her because that was when we went on strike. But the first one, she already did the test and had a scan, and since our referral is from here to the State level, so we had to refer her. We tried our best, though.

$$
\text { (Female/42 years/Owo Baale/KII) }
$$

Another informant reported that due to inadequate equipment to carry out breast cancer screening, people are referred to hospitals, and this even led to the death of one woman who detected the condition late. This was captured below:

We do not carry out breast cancer screenings here because there are no facilities for that. We can only check and make referrals. Someone just died a few months ago as a result of late detection, and she tried alternatives (traditional), and it went out of hand. Not all the women in this community come to the hospital as soon as they notice abnormalities, some come early while some do not, and that can pose a threat to their health. Instead of coming to the health center for their health conditions, they prepare to patronize local medicine sellers or traditional medicine.

(Female/35 years/Awaye/KII)

As seen in the qualitative study, the respondents had a negative attitude towards breast cancer screening. They rarely visited the health center for medical check-ups. Similarly, scholars have opined that attitude towards breast cancer screening among women is not very encouraging (Trimble, 2017). According to some surveys, the non-performance of breast self-examination is due to inadequate knowledge of the ways to go about it as well as the mentality that one can never have breast cancer (Bassey et al., 2011; Aniebue and Aniebue, 2008) Also, our study further revealed that local health workers are not adequately trained to handle issues about breast cancer or screening. This accounted for the series of referrals made to State hospitals to handle breast cancer screening. To support this finding, one study reported that most women in Nigeria were diagnosed with breast cancer at an advanced stage because of poor health facilities (Gali, 2013).

\section{Discussion of Findings}

The majority (51.9\%) of the respondents were young women aged $16-30$, while $50.7 \%$ were married. This shows that the communities where the research was conducted had younger than older women. Also, the women got married at an early age. The population for the study was semi-literate. The implication of this is that the literacy problem is an issue in the study area, thereby influencing knowledge of breast cancer screening. In line with this, a study reported that a relationship existed between education level and women's awareness of breast cancer and its screening tests (Okolie, 2011). A larger proportion of the respondents were low-income earners because most of them were self-employed. They rely on the proceeds they got from their husband's occupation, which is farming, to earn a living. Again, studies have shown that women with higher income had more knowledge of breast cancer screening when compared to those with lower income (Abeje, Seme and Tibelt, 2019).

The study further revealed that the majority $(81 \%)$ of the respondents had heard of breast cancer, while $11.6 \%$ had not. This does not support a study among women in a rural community that revealed that only half of the women had heard of breast cancer (Omotara et al., 2012). Also, more than half (54.3\%) of the respondents reported that breast cancer was deadly, and $23.9 \%$ were of the view that it could be treated in its early signs are detected. Previous studies have shown that breast cancer could be treated if detected early, 
Rowland Edet et al., Adv. J Social Sci.; Vol. 7, Issue 1, pp: 81-91, 2020

it is associated with a high incidence of death, and that early treatment could improve the chances of survival (Kantelhardt et al., 2015)

Results showed that the main source of knowledge on breast cancer was radio. It was discovered that more of the respondents learned about breast cancer basically because they had access to the radio. Through the radio, they were exposed to the health information on what breast cancer is all about. This corroborates similar research that one of the ways women derived health information on breast cancer was through radio (Isara and Ojedokun, 2011). Further results revealed that only a slight majority (63.7\%) knew about screening for breast cancer. This finding is worrisome because it shows that many did not take action to examine themselves of any sign of breast cancer. Again, as previously stated, the low literacy and income level of the women are responsible for such low knowledge.

In the study, some respondents reported that bacterial infections caused breast cancer, some reported that it was caused by poor hygiene, and others attributed it to spiritual attacks. In the same vein, scholars had revealed that many women had limited knowledge of breast cancer-related symptoms (Kingsley, 2010). According to the study, the commonly known breast cancer screening is breast self-examination. Previous studies explained that more women are aware of breast self-examination more than any other breast cancer screening method (Irurhe et al., 2012).

Further findings revealed that respondents were scared of going for breast cancer screenings. Interview sessions with the community health workers revealed that even though there were no breast cancer screenings in the health centers, members of the community rarely visited for scans or tests on any medical condition. This is in tandem with similar research, which revealed one of the reasons for not going for breast cancer screening are lack of health facilities, fear, and the belief that one is immune to breast cancer (Agboola et al., 2009).

The attitude towards breast cancer screening among women in the study is not encouraging. Even those who had a positive attitude towards breast cancer screening were limited by financial constraints and would prefer to use their time for other things rather than go for breast cancer screenings. This supports a study that shows that limited resources remain a barrier when it comes to breast cancer screening among women (Anyanwu, Egwuonwu and Ihekwoaba, 2012). Another scholar opined that women in low-income populations are faced with financial incapacitation, which might affect their decision to perform breast cancer screening (Izanloo et al., 2018).

The interview sessions with the respondents revealed that inadequate medical facilities and a lack of medical equipment prevented them from going for breast cancer screening. This was also confirmed by the community health officers, who said explicitly that there were no medical facilities or equipment for breast cancer screenings. When they diagnosed with any patients of breast cancer, they would have to refer them to the state level for further treatments. Also, many of the women in the study rely on Generals hospitals located far away from the local people. Rather than going to the hospital because of its distance, the women patronized the nearest available pathways to cater to their health needs, such as traditional means or Patent Medicine Vendors (PMVs), which is not reliable. As the findings revealed, extensive studies on primary health centers need to be carried out in rural areas so that it can be the focal point for breast cancer screening at the grassroots level.

\section{Conclusion}

Early detection of breast cancer through screening methods is an important aspect in the prevention and management of the disease. However, women in Nigeria detect breast cancer late due to poor knowledge of breast cancer screening methods, poor health system, poor health-seeking behaviour, and other sociocultural factors. Therefore, a concerted effort must be made to ensure that there are adequate awareness 
programs to educate rural women on breast cancer and the need to go for breast cancer screening regularly. This is very important because the issue of breast cancer is still under-flogged as many women do not attend medical check-ups until they have tried other means that could not work out. Besides, the primary health centers in rural areas should be up to standard and well equipped as this would encourage the rural dwellers to go for a general check-up to know their health status.

\section{Declarations}

\subsection{Acknowledgements}

We are grateful to the study participants and the research assistants for their time to participate in the study.

\subsection{Competing Interests}

The authors declared that no conflict of interest exist.

\section{How to Cite this Article:}

Rowland Edet et al. (2020). Knowledge of Breast Cancer and Screening Methods among Rural Women in Southwest Nigeria: A Mixed Method Analysis. Advanced Journal of Social Science, 7 (1), 81-91. https://doi.org/10.21467/ajss.7.1.81-91

\section{References}

Abeje S, Seme A, \& Tibelt, A. (2019). Factors associated with breast cancer screening awareness and practices of women in Addis Ababa, Ethiopia. BMC Women's Health, 19(4).

Agboola, A.O.J., Deji-Agboola, A.M., Oritogun, K.S., Musa, A.A., Oyebadejo, T.Y., \& Ayoade, B.A. (2009). Knowledge, Attitude and Practice of Breast Self-examination in Female Health Workers in Olabisi Onabanjo University Teaching Hospital, Sagamu, Nigeria. International Medical Journal, 8(1), 5-10.

Ajayi, I.O., Onibokun, A.C., \& Soyannwo, O.A. (2013). Breast and Cervical Cancers Awareness and Screening Practices among Rural Women in Ona-Ara Local Government Area, Ibadan. Nigeria African Journal of Biomedicine Research, 16(2), 95-99.

Akhigbe, A.O., \& Omuemu, V.O. (2009). Knowledge, attitudes and practice of breast cancer screening among female health workers in a Nigerian urban city. BMC Cancer, 25(9), 203

Aniebue, P.N., \& Aniebue, U.U. (2008). Awareness of breast cancer and breast self-examination among female secondary school teachers in Enugu metropolis, south-eastern Nigeria. International Journal of Medical Health Development, 13(2), 105-110.

Anyanwu, S.N., Egwuonwu, O.A., \& Ihekwoaba, E.C. (2012). Acceptance and adherence to treatment among breast cancer patients in Eastern Nigeria. Breast 20 Suppl., 2(5), 1-3.

Azage, M., Abeje, G., \& Mekonnen, A. (2013). Assessment of factors associated with breast self-examination among health extension workers in West Gojjam Zone, Northwest Ethiopia. Int J Breast Cancer, 5(7), 15-19.

Bassey, R.B., Irurhe, N.K., Olowoyeye, M.A., Adeyomoye, A.A., \& Onajole, A.T. (2011). Knowledge, attitude and practice of breast selfexamination among nursing students in Lagos University Teaching Hospital, Nigeria. Educational Research, 2(6), 1232-1236.

Bello, T.O., Olugbenga-Bello, A.I., Ogunsola, A.S., Adeoti, M.L., \& Ojemakinde, O.M. (2011). Knowledge and practice of breast cancer screening among female nurses and lay women in Osogbo, Nigeria. West African Journal of Medicine, 30(4), 296-300.

Donnelly, T.T., Khater, A., Bujassoum, A.S., Kuwari, M.G., Al-Meer, N., Malik, M., Singh, R., Chaudhry, S., \& Fung, T. (2013). Beliefs and attitudes about breast cancer and screening practices among Arab women living in Qatar: a cross-sectional study. BMC Women's Health, 13(49).

Gali, B.M. (2013). Breast cancer awareness and screening practices among female health workers of university of Maiduguri teaching hospital. BOMJ, 10(2).

Haji-Mahmoodi, M., Montazeri, A., Jarvandi, S., Ebrahimi, M., Haghighat, S., \& Harirchi, I. (2008). Breast self-examination: knowledge, attitudes, and practice among female health care providers in Tehran, Iran. Breast, J., 8, 222-225. 10.1046/j.1524-4741.2002.08406.x

Ifeanyichukwu, O.A. (2015). Assessment of breast cancer screening practices among women of reproductive age in Benin City, Edo State. International Journal of Tropical Disease \& Health, 6(4), 141-149.

Irurhe, N.K., Raji, S.B., Olowoyeye, O.A., Adeyomoye, A.O., Arogundade, R.A., Soyebi, K.O., Ibitoye, A.Z., Abonyi, L.C., \& Eniyandunni, F.J. (2012). Knowledge and Awareness of Breast Cancer among Female Secondary School Students in Nigeria. Academic Journal of Cancer Research, 5(1), 0105.

Isara, A.R., \& Ojedokun, C.I. (2011). Knowledge of breast cancer and practice of breast self-examination among female senior secondary school students in Abuja, Nigeria. Journal of Prevalence Medical Hygiene, 52, 186-190.

Izanloo, A., Ghaffarzadehgan, K., Khoshroo, F., Erfani, M.H., Izanloo, S. (2018). Knowledge and attitude of women regarding breast cancer screening tests in Eastern Iran. Ecancermedicalscience, 12, 806.

Kantelhardt, E.J., Muluken, G., Sefonias, G., Wondimu, A., Gebert, H.C., \& Unverzagt, S. (2015). A review on breast cancer care in Africa. Breast Care (Basel), 10(6), 364-70.

Kingsley, C. (2010). Cultural and socioeconomic factors affecting cancer screening, early detection and care in Latino population. Retrieved 13 November 2019 from: https://ethnomed.org/clinical/cancer/cultural-andsocioeconomic-factors-affecting-cancer-screeningearlydetection-and-care-in-the-latino-population.

Obaji, N., Elom, H., Agwu, U., Nwigwe, C., Ezeonu, P., \& Umeora. O. (2013). Awareness and practice of breast self-examination among market women in Abakaliki, South East Nigeria. Annals Medical Health Science Research, 3, 7-12. 
Rowland Edet et al., Adv. J Social Sci.; Vol. 7, Issue 1, pp: 81-91, 2020

Oche, M.O., Ayodele, S.O., \& Umar, A.S. (2012). Knowledge of female health workers about breast cancer and their attitude and practice of mammography. Public Health Research, 2(5), 114-119.

Okobia, M.N., Bunker, C.H., Okonofua, F.E. \& Osime, U. (2006). Knowledge, attitude and practice of Nigerian women towards breast cancer: A cross-sectional study. World Journal of Surgical Oncology, 4, 1-9.

Okolie, U.V. (2011). Breast self-examination among female undergraduates in Enugu, Southeast, Nigeria. International Journal of Nursing Midwifery, 4(1), 1-7.

Oluwatosin, O.A., \& Oladepo, O. (2006). Knowledge of breast cancer and its early detection measures among rural women in Akinyele Local Government Area, Nigeria. BMC Cancer, 6, 271.

Omotara, B., Yahya, S., Amodu, M., \& Bimba, J. (2012). Awareness, attitude and Practice of Rural women regarding Breast Cancer in Northeast Nigeria. Journal of Community Medicine Health Education, 2, 148.

Onwere, S., Okoro, O., Chigbu, B., Aluka, C., Kamanu, C., \& Onwere, A. (2009). Breast self-examination as a method of early detection of breast cancer: Knowledge and practice among antenatal clinic attendees in South Eastern Nigeria. Pakistan Journal of Medical Science, 25, 122-5.

Parvani, Z. (2011). Breast self-examination; breast awareness and practices of systematic review. Professional Medical Journal, 18(2), 336339.

Salaudeen, A.G., Akande, T.M., \& Musa, O.I. (2009). Knowledge and Attitudes to Breast Cancer and Breast Self-Examination among Female Undergraduates in a State in Nigeria. Europe Journal of Social Science, 3, 157-165.

Taha, H., Nyström, L., Al-Qutob, R., Berggren, V., Esmaily, H., and Wahlström, R. (2014). Home visits to improve breast health knowledge and screening practices in a less privileged area in Jordan. BMC Public Health, 14,42.

Tobin, E.A, \& Okeowo, P.O. (2014). Breast self-examination among secondary school teachers in South-South, Nigeria: A survey of perception and practice. Journal of Public Health Epidemiology, 6(5), 169-173.

Trimble, E.L. (2017). Breast Cancer in sub-Saharan Africa. J Glob Oncol., 3(3), 187-188.

Yakubu, A.A., Gadanya, M.A., \& Sheshe, A.A. (2014). Knowledge, attitude, and practice of breast self-examination among female nurses in Aminu Kano teaching hospital, Kano, Nigeria. Nigeria Journal of Basic Clinical Scienc, 11(2), 85-88.

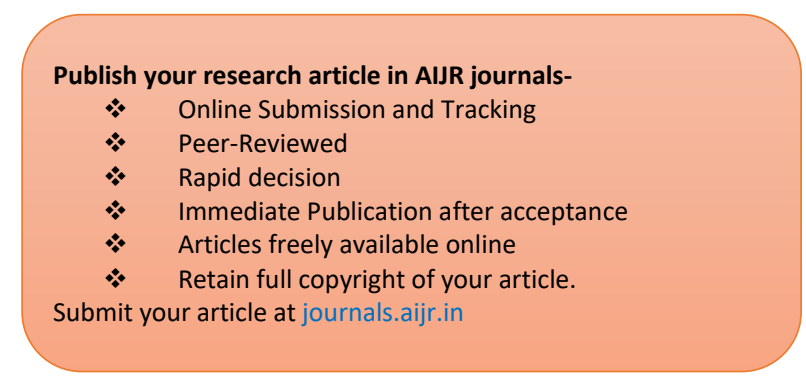
Publish your books with AIJR publisher-
* Publish with ISBN and DOI.
* Publish Thesis/Dissertation as Monograph.
* Publish Book Monograph.
* Publish Edited Volume/ Book.
* Publish Conference Proceedings
- Retain full copyright of your books.
Submit your manuscript at books.aijr.org 